\title{
Detection of human bocavirus-1 in both nasal and stool specimens from children under 5 years old with influenza-like illnesses or diarrhea in Gabon
}

\author{
Sonia Etenna Lekana-Douki ${ }^{* *}$, Sylvie Behillii ${ }^{2,3}$, Vincent Enouf ${ }^{2,3}$, Eric M. Leroy ${ }^{1,4}$ and Nicolas Berthet ${ }^{1,3,5}$
}

\begin{abstract}
Objective: Human bocavirus ( $\mathrm{HBOV}$ ) is a viral pathogen which causes respiratory tract diseases and acute gastroenteritis worldwide. This virus mainly affected children under 5 years old. There is little information on HBoV in Gabon. Two first studies was conducted to determine the prevalence of respiratory and enteric viruses in children under 5 years old who visited health centers for influenza-like illness (ILI) or diarrhea in Gabon from March 2010 to June 2011. However, HBoV was not included in the screening. The aim of this retrospective study was to evaluate the prevalence and the HBoV genotype in children under 5 years old with ILI or diarrhea in Gabon.
\end{abstract}

Results: A total of 810 nasal swabs and 317 feces samples collected during the two first study were analyzed among which 32 (4.4\%) and 7 (2.2\%) were positive for HBoV respectively. While there were no significant differences in prevalence between age groups in children with ILI, all children with diarrhea were under 12 months of age. Moreover, 84.4 and $42.8 \%$ were diagnosed in co-infections with at least one other respiratory virus, or enteric viruses respectively. Finally, HBoV subtype 1 has been detected in both respiratory and gastrointestinal tracts with very low variability.

Keywords: HBoV-1, Influenza-like illness, Diarrhea, Children, Gabon

\section{Introduction}

Pathogens causing respiratory tract infections and acute gastroenteritis have a significant impact on public health. Respiratory and gastrointestinal infections are the major causes of morbidity and mortality worldwide in children under the age of five $[1,2]$. The human bocavirus $(\mathrm{HBoV})$ was discovered in 2005 in children with respiratory infections [3]. $\mathrm{HBoV}$ is a single-stranded DNA virus, belonging to the family Parvoviridae and the subfamily Parvovirinae. HBoV-1 has been predominantly diagnosed in the respiratory tract where as the three other types, $\mathrm{HBoV}$ $2, \mathrm{HBoV}-3$ and $\mathrm{HBoV}-4$, have been described as enteric viruses mainly excreted in stool [4]. Patients infected by the $\mathrm{HBoV}$ develop various clinical signs, such as rhinitis,

\footnotetext{
*Correspondence: s_lekana@yahoo.fr

${ }^{1}$ Centre International de Recherches Médicales de Franceville, BP 769, Franceville, Gabon

Full list of author information is available at the end of the article
}

pharyngitis, cough, dyspnea, wheezing, pneumonia, acute otitis media, fever, nausea, vomiting and diarrhea [5], and whose prevalence ranges from 5 to $10 \%$ of acute respiratory infections in children [6-8]. However HBoV can also be detected in an asymptomatic people [5].

In Central Africa, data on influenza-like illnesses (ILIs) are recent. $\mathrm{HBoV}$ has only been described in Cameroon in data showing a $10.6 \%$ prevalence [9].

In Gabon, several viruses were screening in two studies from March 2010 to June 2011. A total of 17 respiratory viruses [seasonal influenza virus $A$ and $B$, pandemic influenza virus $\mathrm{A}(\mathrm{H} 1 \mathrm{~N} 1) \mathrm{pdm} 09$, parainfluenza viruses (PIVs) types 1-4, respiratory syncytial virus (RSV), human metapneumovirus (hMPV), adenoviruses (AdV), rhinoviruses (HRV), enteroviruses (EV), coronaviruses HCoV-NL63, HCoV-HKU1, HCoV-OC43, HCoV-229E, and human parechovirus $(\mathrm{HPeV})]$ were screened during this surveillance of ILIs among children under 5 years 
old [10]. Similarly, six enteric viruses [rotavirus A (RVA), adenovirus (AdV), norovirus I (NoVs-I) and II (NoVs$\mathrm{II})$, sapovirus $(\mathrm{SaV})$ and human astrovirus (HAstV)] were screening during the same period in another study in children under 5 years old [11]. The most common viruses found were AdV (17.5\%), PIVs (16.8\%), EV (14.7\%), RSV (13.5\%), influenza viruses (11.9\%) for ILI surveillance and RVA (27.1\%), AdV (19.6\%) and NoVs-II (13.9\%) for diarrhea surveillance. Moreover, the prevalence of viral infection caused by at least one virus was 68.1 and $60.9 \%$ for ILI and diarrhea respectively. However, in those previous studies, $\mathrm{HBoV}$ was not included in the screening and few data are available on the circulation of this pathogen in Gabon. The main objective of this study were to evaluate the prevalence of $\mathrm{HBoV}$ in Gabon and to determine the genotype that circulate among children under 5 years old with ILI or diarrhea from March 2010 to June 2011.

\section{Main text \\ Methods \\ Patients and samples}

A retrospective study was conducted to evaluate the circulation of $\mathrm{HBoV}$ in children under 5 years old who visited health centers for ILI or diarrhea in Gabon. A total of 810 nasal swabs and 317 stool samples were collected in Libreville (the capital of Gabon), in Franceville (southeast), in Oyem (north) and in Koulamoutou (south). Demographical data such as the patient's name, age, sex and clinical data including travel history during the month before onset were recorded. Nasal swabs "553C" (Copan, Diagnostic) placed in dry tubes and feces samples collected were stored at $4{ }^{\circ} \mathrm{C}$ until transportation to the Centre International de Recherches Médicales de Franceville (CIRMF), once a week for virological investigation. Seventeen respiratory viruses and six enteric viruses had previously been tested from their samples $[10,11]$.

\section{Laboratory analysis}

DNA was extracted on a BioRobot EZ1 workstation (Qiagen) using the EZ1 Virus Mini Kit version 2.0 (Qiagen) according to the manufacturer's instructions [10]. Real-time polymerase chain reaction was performed in order to detect all types of $\mathrm{HBoV}$ using the forward primer $5^{\prime}$-CTGGGGCTCATATCATCA- $3^{\prime}$, the reverse primer $5^{\prime}$-TCTCCCTCGTCTTCATCA- $3^{\prime}$ and the probe $5^{\prime}$-AACACCCAATCAGCCACCT-3' for the 93 bp virus nucleoprotein (NP) target. Each $20 \mu \mathrm{l}$ of reaction mixture contained $5 \mu \mathrm{l}$ of eluted DNA, $10 \mu \mathrm{l}$ of Master Mix Fast (Applied Biosystems), $0.5 \mu \mathrm{M}$ primers and $0.2 \mu \mathrm{M}$ probe. A 7500 Fast Real Time PCR system was run for 2 min at $50{ }^{\circ} \mathrm{C}$, for $20 \mathrm{~s}$ at $95^{\circ} \mathrm{C}$, followed by 50 cycles of $95^{\circ} \mathrm{C}$ for
$10 \mathrm{~s}$ and $60{ }^{\circ} \mathrm{C}$ for $30 \mathrm{~s}$. For genotyping bocaviruses, the NP-1 gene fragment was amplified using a conventional PCR method (DNA Taq polymerase kit; Invitrogen) [3]. The generated amplicons ( $354 \mathrm{bp}$ ) were sequenced by the method of Sanger.

\section{Phylogenetic and statistical analysis}

A multiple sequence alignment of our bocavirus sequences with a selection of reference strains available in the GenBank database was performed using ClustalX (version 1.81). Phylogenetic relationships were reconstructed using the best-fitting ML model based on the Akaike information criterion, and General Time Reversible. The phylogenetic tree was built using the maximumlikelihood method with the PhyML algorithm [12-14] and drawn using FigTree v.1.4.0.

Statistical analysis was performed using Statview V5.0 software. Pearson's Chi squared test and Fisher's exact test were used to analyze the results. A two-tailed critical alpha value of 0.05 was used. A p-value below 0.05 was considered to indicate statistical significance.

\section{Results \\ Demographic data and prevalence of $\mathrm{HBOV}$}

Among the 810 patients with ILI, 416 were males (51.4\%), 394 were females $(48.6 \%)$ and the male:female (M:F) sex ratio was 1.05 (Table 1 ). The age ranged from 10 days to 4 years with median and mean ages of 1.33 years and $1.5 \pm 1.0$ years, respectively. Among these children, 341 (42.1\%) were younger than 1 year old, 318 (39.3\%) were $1-2$ years old and $151(18.6 \%)$ were $3-4$ years old (Table 1).

Among the 317 patients with diarrhea, 169 were males (53.3\%), 148 were females (46.7\%) and the maleto-female (M:F) sex ratio was 1.14. Patient ages ranged from 15 days to 4 years, with a median of 0.9 years and a mean of $1.1 \pm 0.9$ years. Among these cases, 205 (64.7\%) were $<1$ year old, $81(25.5 \%)$ were $1-2$ years old and 31 (9.8\%) were 3-4 years old (Table 1).

The global prevalence of the $\mathrm{HBoV}$ was $4 \%(32 / 810)$ in the nasal specimens and $2.2 \%(7 / 317)$ in the stool samples (Table 1). The detection rate was similar in males and females in both types of infection, $\left(X^{2}=0.487, p=0.49\right)$, $\left(\mathrm{X}^{2}=0.032, \mathrm{p}=0.85\right)$. Moreover, while there were no significant differences between the age groups for detection of bocavirus in nasal samples $\left(\mathrm{X}^{2}=3.3, \mathrm{p}=0.19\right)$, all children with diarrhea infected by $\mathrm{HBoV}$ were under 1 year old (Table 1).

\section{Geographic and seasonal distribution of HBoV}

Analysis of $\mathrm{HBoV}$ prevalence across the four towns showed no significant differences between Libreville (5.1\%), Franceville (4.4\%), Koulamoutou (1.0\%) 
Table 1 Demographic characteristics, prevalence of human bocavirus and co-infection

\begin{tabular}{|c|c|c|c|c|}
\hline \multirow[t]{2}{*}{ Characteristic } & \multicolumn{2}{|c|}{ Human bocavirus (ILI) } & \multicolumn{2}{|c|}{ Human bocavirus (diarrhea) } \\
\hline & n1/N1 (\%) & $95 \% \mathrm{Cl}$ & n2/N2 (\%) & $95 \% \mathrm{Cl}$ \\
\hline \multicolumn{5}{|l|}{ Sex } \\
\hline Male & $14 / 416(3.4)$ & $1.7-5.1$ & 3/169 (1.8) & $0.3-3.3$ \\
\hline Female & 18/394 (4.6) & $2.5-6.7$ & $4 / 148(2.7)$ & $0.9-4.5$ \\
\hline \multicolumn{5}{|l|}{ Age group } \\
\hline$[0-12 \mathrm{~m}]$ & $18 / 341(5.3)$ & $2.9-7.7$ & $7 / 205(3.4)$ & $1.4-5.4$ \\
\hline$[13 \mathrm{~m}-2 \mathrm{y}]$ & $11 / 318(3.5)$ & $1.5-5.5$ & $0 / 81(0.0)$ & - \\
\hline$[3-4 y]$ & $3 / 151(2.0)$ & -0.2 to 4.2 & $0 / 31(0.0)$ & - \\
\hline \multicolumn{5}{|l|}{ Towns } \\
\hline Libreville & 20/391 (5.1) & $2.9-7.3$ & $0 / 150(0.0)$ & - \\
\hline Franceville & $7 / 159(4.4)$ & $1.2-7.6$ & $1 / 56(1.8)$ & $0.3-3.3$ \\
\hline Koulamoutou & $1 / 98(1.0)$ & -1.0 to 3.0 & $1 / 33(3.0)$ & $1.1-4.9$ \\
\hline Oyem & $4 / 162(2.5)$ & $0.1-4.9$ & $5 / 78(6.4)$ & $3.7-9.1$ \\
\hline Total & $32 / 810(4.0)$ & $2.7-5.3$ & $7 / 317(2.2)$ & $0.6-3.8$ \\
\hline Infection & n (\%) & & n (\%) & \\
\hline Single infection & $5(15.6)$ & & $4(57)$ & \\
\hline Dual infection & $20(62.5)$ & & $2(28)$ & \\
\hline Adenovirus & $6(22.3)$ & & ND & \\
\hline Enterovirus & $4(14.8)$ & & ND & \\
\hline RSV & $3(11.1)$ & & ND & \\
\hline Virus influenza B & $3(11.1)$ & & ND & \\
\hline Virus A(H1N1)pdm09 & $2(7.4)$ & & ND & \\
\hline Rhinovirus & $1(3.7)$ & & ND & \\
\hline Coronavirus NL63 & $1(3.7)$ & & ND & \\
\hline Rotavirus A & ND & & $1(33.3)$ & \\
\hline Sapovirus & ND & & $1(33.3)$ & \\
\hline Triple infection & $7(21.9)$ & & $1(14.3)$ & \\
\hline Enterovirus, rhinovirus & $1(3.7)$ & & - & \\
\hline Adenovirus, RSV & $1(3.7)$ & & - & \\
\hline Virus influenza B, HCoV-229E & $1(3.7)$ & & - & \\
\hline Adenovirus, enterovirus & $1(3.7)$ & & - & \\
\hline Enterovirus, HCoV-HKU1 & $1(3.7)$ & & - & \\
\hline Virus A(H1N1)pdm09, HCoV-OC43 & $1(3.7)$ & & - & \\
\hline PIV1, rhinovirus & $1(3.7)$ & & - & \\
\hline Adenovirus, norovirus 2 & - & & $1(33.3)$ & \\
\hline Total coinfection & $27(84.4)$ & & $3(43)$ & \\
\hline Total & $32(100)$ & & $7(100)$ & \\
\hline
\end{tabular}

$n 1$ number of bocavirus cases among patients with ILI, $N 1$ number of ILI cases, $n 2$ number of bocavirus cases among patients with diarrhea, $N 2$ number of diarrhea cases, $\mathrm{Cl}$ confidence interval, $m$ months, y years, $n$ number of bocavirus, ND No data, HCoV-229E coronavirus 229E, HCoV-HKU1 Coronavirus HKU1, HCoV-OC43 Coronavirus OC43, PIV1 parainfluenza virus 1

and Oyem (2.5\%) for ILI $\left(\mathrm{X}^{2}=4.6, \mathrm{p}=0.20\right)$ (Table 1$)$. Among the 7 positive $\mathrm{HBoV}$ stool samples, bocavirus was detected most frequently in Oyem $(5 / 7)\left(\mathrm{X}^{2}=9.9\right.$, $\mathrm{p}=0.02)$, one case was detected in Franceville and one in Koulamoutou (Table 1). However, theses 7 cases were diagnosed during the big dry season and the short rainy season in 2010 (Fig. 1b). The number of ILI cases and the rate of virus-positive ILI increased during the rainy seasons $\left(X^{2}=7.0, p=0.008\right)$ (Fig. 1a). However the rate of $\mathrm{HBoV}$ detection was low and did not vary significantly during the study $\left(\mathrm{X}^{2}=0.002\right.$, $\mathrm{p}=0.9)$ (Fig. 1b). 

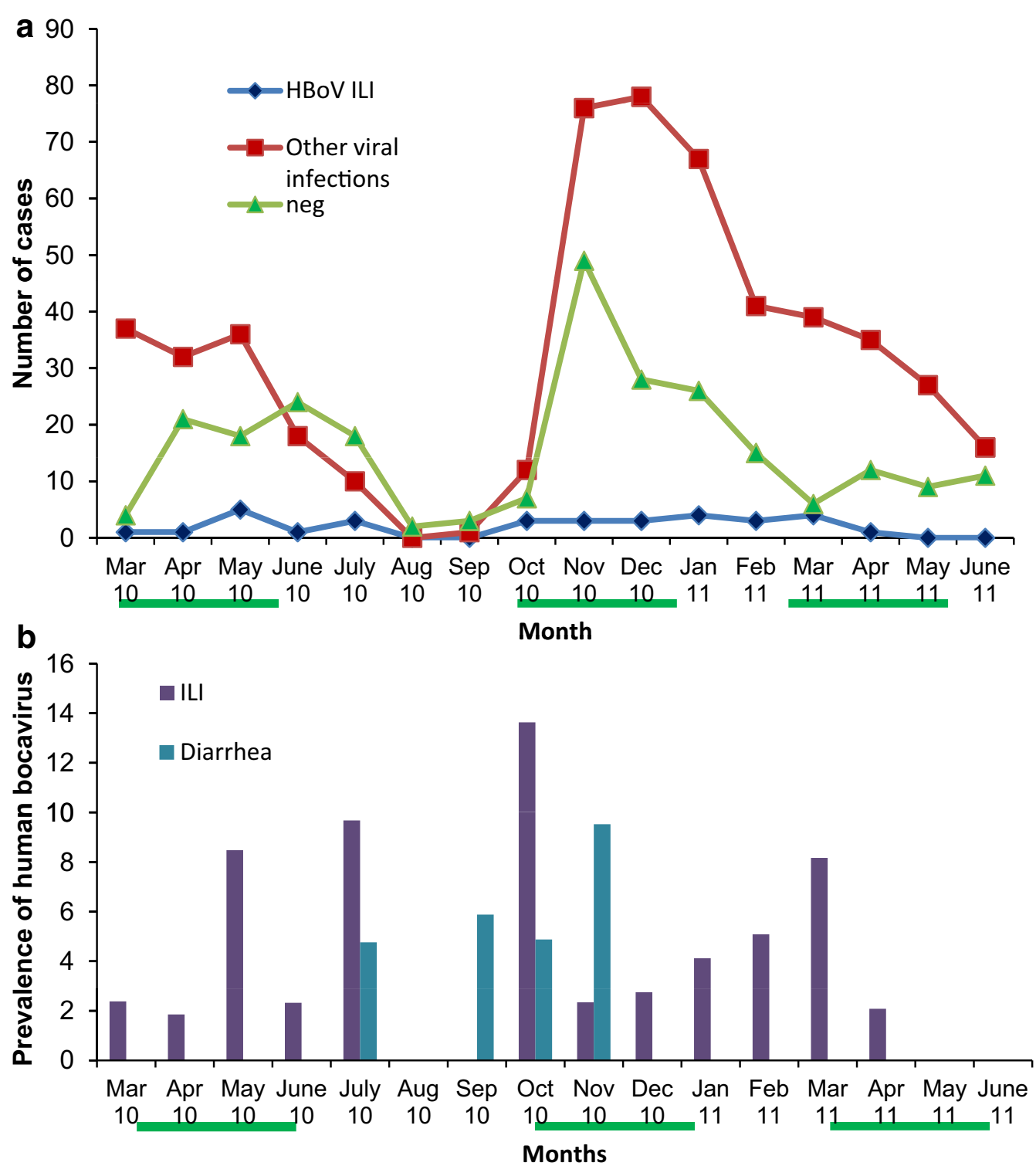

Fig. 1 Human bocavirus in children under 5 years old in Gabon. a Number of cases among viral infections and influenza-like illnesses. b Prevalence of the human bocavirus during the different seasons among patients with ILI and diarrhea. The green line below the chart indicates the rainy seasons

\section{Coinfections}

The bocavirus was detected in a single infection in $15.6 \%$ $(5 / 32)$ of positive viral nasal samples; the remaining $84.4 \%(27 / 32)$ of the samples were detected in coinfection with another virus (Table 1$)$. $\mathrm{HBoV}$ was detected predominantly in co-infections $\left(\mathrm{X}^{2}=34.4, \mathrm{p}<0.0001\right)$. In this category, $62.5 \%(20 / 32)$ and $21.9 \%(7 / 32)$ were double and triple infections, respectively (Table 1). The most common co-infections were with $\mathrm{AdV}$, followed by EV. Four (4/7) positive viral samples for $\mathrm{HBoV}$ showed a single infection, and three samples were co-infected with rotavirus $A(n=1)$, sapovirus $(n=1)$ and adenovirus/norovirus $2(\mathrm{n}=1)$ (Table 1$)$.

\section{Phylogenetic analysis}

The phylogenetic analysis based on a partial sequence of the NP1 gene from $26 \mathrm{HBoV} 1-4$ strains registered in the GenBank database showed that all 16 sequences obtained in our study (accession numbers MF041728-MF041738 and MF784506-MF784510, GenBank database) from nasal and stool specimens clustered with $\mathrm{HBoV}-1$ (Fig. 2). Despite the small fragment sizes, two groups were 


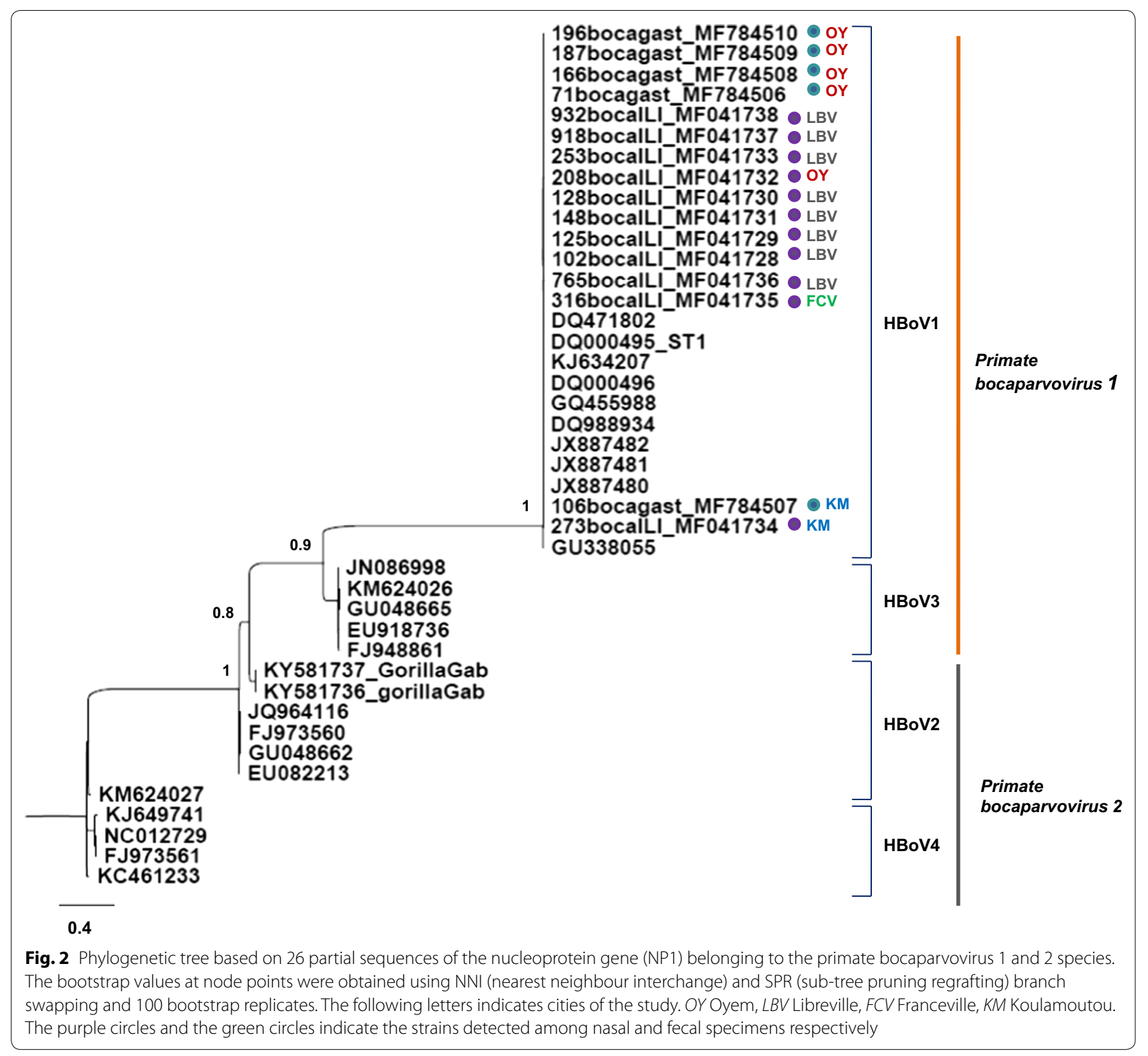

discerned. In one group, 14 strains displayed 99\% identity at the nucleotide level with the USA strain (Accession No. DQ471802) whereas the two remaining strains showed $100 \%$ identity at the nucleotide level with the reference strain from China (Accession No. JX887480) (Fig. 2). These latter sequences, that displayed one nucleotide difference with the others, were isolated from specimens collected in the same city Koulamoutou, one from a child with ILI and the other from a child with acute gastroenteritis (Fig. 2). The nucleotide substitution (T274A) on the NP-1 gene sequence generated a non-synonymous mutation, with an amino-acid substitution of serine with threonine.

\section{Discussion}

In this study, $\mathrm{HBoV}$ prevalence was 4 and $2.2 \%$ in children under 5 years old with ILI and diarrhea, respectively, in Gabon. This low prevalence rate was similar to most previous studies, which have reported detection rates ranging from 5 to $10 \%[6-9,15-18]$. In our target population, influenza viruses, PIVs, RSV, HRV, AdV were generally diagnosed more frequently, as described in previous studies [19-21] and in Gabon [10]. Furthermore, worldwide, children under 5 years old with acute gastroenteritis are most frequently affected by rotavirus A (RVA) and norovirus (NoV) [22, 23]. Among the 317 stool samples of this study, the prevalence of 
enteric viruses was $21.7 \%$ for RVA, $19.6 \%$ for AdV, 9.1\% for $\mathrm{NoV}$-I, $13.9 \%$ for $\mathrm{NoV}$-II, $9.5 \%$ for $\mathrm{SaV}$ and $6.3 \%$ for HastV [11].

Seroprevalence studies on $\mathrm{HBoV}$ confirms that the virus is acquired very early in life, before the age of two [7, 24]. This data corroborated our results showing that all children with diarrhea infected by $\mathrm{HBoV}$ were under 1 year old. However, we didn't find any relationship between the virus that infected the patients and the severity of ILI (data not shown).

Our previous study showed that the viral infections of the respiratory tract are more frequent during the rainy season [10]. However, as observed in our study, a metaanalysis on $\mathrm{HBoV}$ infections failed to detect any seasonality on the African, Asian or American continents [9, 25]. The lack of evidence for seasonality maybe due either to very low prevalence or only sporadic cases of $\mathrm{HBoV}$ in several tropical countries [17, 26, 27].

In most studies, the rate of $\mathrm{HBoV}$ co-detection with at least one other virus ranges from 18 to $90 \%$ of respiratory samples [28]. Similarly, our study detected co-infection in $84.4 \%$ of $\mathrm{HBoV}$ infection cases. However, a study suggested that, this high rate of co-infection may challenge the role of $\mathrm{HBoV}$ as a causative pathogen, it may persist in the lymphatic tissue or become reactivated [29]. Viral loads tend to be higher in $\mathrm{HBoV}$ mono-infections than in co-infections $[7,28,29]$. We found that the threshold cycle values $(\mathrm{Ct})$ were lower and the viral loads were therefore higher in monoinfection than in coinfection (data not shown). A global analysis of $\mathrm{HBoV}$ data shows co-detection in various frequencies with AdV, EV, HRV, $\mathrm{RSV}$, influenza virus $\mathrm{A} / \mathrm{B}$ and coronaviruses [28]. $\mathrm{HBoV}$ was found with frequently associated with rotavirus and norovirus [30, 31]. Similarly, our results showed coinfection with these previous viruses (Table 1).

The phylogenetic analysis of 16 strains showed that HBoV subtype 1 has been detected in both respiratory and gastrointestinal tracts, as described in China [32]. Studies mostly described $\mathrm{HBoV}-1$ in respiratory specimens and $\mathrm{HBoV}-2, \mathrm{HBoV}-3, \mathrm{HBoV}-4$ in stool specimens. However, other study reported that $\mathrm{HBoV}-1$ was the most frequently genotype detected in stool specimens [33]. Finally our results are compatible with those of a Korean study showing all $\mathrm{HBoV}$, detected in children with gastroenteritis and respiratory tract infection, were HBoV-1 genotype [34]. Our finding suggesting that the same HBoV-1 strain infected both respiratory and gastrointestinal tract supported the hypothesis that $\mathrm{HBoV}$ first causes respiratory tract infections and penetrates later to the gastrointestinal tract causing diarrhea [34]. Several studies showed that $\mathrm{HBoV}$ strains clustered into $\mathrm{HBoV}-1$ with minor variations among them, sequences were highly conserved (99-100\%) [34, 35]. This corroborated our results which show a very low variability of the HBoV-1 sequences.

In conclusion, this study provided the first data on the circulation of human $\mathrm{HBoV}$ in children under 5 years old in Gabon. The HBoV-1 genotype, was detected in both nasal and fecal specimens showing a low detection rate and similarly strains circulated in both respiratory and gastrointestinal infections. These data enhanced our knowledge on $\mathrm{HBoV}$ involved in respiratory infection and acute gastroenteritis and suggest that ILI and diarrheal surveillance should be continued to better understand the burden of these infections.

\section{Limitations}

Considering the period of the study and the number of sites, the number of patients with ILI and diarrhea was probably underestimated.

\section{Abbreviations \\ HBoV: human bocavirus; ILI: influenza-like illness; PIVs: parainfluenza viruses; RSV: respiratory syncytial virus; hMPV: human metapneumovirus; AdV: adeno- virus; HRV: rhinovirus; EV: enterovirus; HCoV: coronaviruses; HPeV: human parechovirus; RVA: rotavirus A; NoV-I: norovirus I; NoV-II: norovirus II; SaV: sapovirus; HAstV: human astrovirus; CIRMF: Centre International de Recherches Médicales de Franceville; NP: nucleoprotein.}

\section{Authors' contributions}

SELD conducted the laboratory analyses and performed the phylogenetic and statistical analyses. SB, VE and NB set up the protocol and analyzed the data. EML analyzed the data. SELD and NB wrote the manuscript. All authors analyzed the data. All authors read and approved the final manuscript.

\section{Author details}

${ }^{1}$ Centre International de Recherches Médicales de Franceville, BP 769, Franceville, Gabon. ${ }^{2}$ Unité de Génétique Moléculaire des Virus à ARN, Centre National de Référence des Virus des Infections Respiratoires, Institut Pasteur, 25 rue du docteur Roux, Paris, France. ${ }^{3}$ Centre National de Recherche Scientifique (CNRS) UMR3569, 25 rue du docteur Roux, Paris, France. ${ }^{4}$ UMR (IRD 224/CNRS 5290/UM1-UM2), Institut de Recherche pour le Développement, Montpellier, France. ${ }^{5}$ Unité Environnement et Risques Infectieux, Cellule d'Intervention Biologique d'Urgence, Institut Pasteur, 25 rue du docteur Roux, Paris, France.

\section{Acknowledgements}

We acknowledge Carolyn Engel-Gautier and and Heïdi Lançon for editing the English usage and style. We thank all hospital staff of the health centers.

\section{Competing interests}

The authors declare that they have no competing interests.

\section{Availability of data and materials}

The data for this study are available from the corresponding author.

\section{Consent to publish}

Not applicable.

\section{Ethics approval and consent to participate}

This study was approved by the Gabonese National Ethics Committee (number 0024/CNE/SG/P). We did have verbal consent from patients and their parents (for minors), which was approved by the Ethics Committee.

Funding

None. 


\section{Publisher's Note}

Springer Nature remains neutral with regard to jurisdictional claims in published maps and institutional affiliations.

Received: 4 May 2018 Accepted: 13 July 2018

Published online: 20 July 2018

\section{References}

1. Mortality GBD, Causes of Death C. Global, regional, and national life expectancy, all-cause mortality, and cause-specific mortality for 249 causes of death, 1980-2015: a systematic analysis for the Global Burden of Disease Study 2015. Lancet. 2016;388(10053):1459-544.

2. Luksic I, Kearns PK, Scott F, Rudan I, Campbell H, Nair H. Viral etiology of hospitalized acute lower respiratory infections in children under 5 years of age - a systematic review and meta-analysis. Croat Med J. 2013;54(2):122-34.

3. Allander T, Tammi MT, Eriksson M, Bjerkner A, Tiveljung-Lindell A, Andersson B. Cloning of a human parvovirus by molecular screening of respiratory tract samples. Proc Natl Acad Sci USA. 2005;102(36):12891-6.

4. Kapoor A, Simmonds P, Slikas E, Li L, Bodhidatta L, Sethabutr O, Triki H, Bahri O, Oderinde BS, Baba MM, et al. Human bocaviruses are highly diverse, dispersed, recombination prone, and prevalent in enteric infections. J Infect Dis. 2010;201(11):1633-43.

5. Jartti T, Hedman K, Jartti L, Ruuskanen O, Allander T, Soderlund-Venermo M. Human bocavirus-the first 5 years. Rev Med Virol. 2012;22(1):46-64.

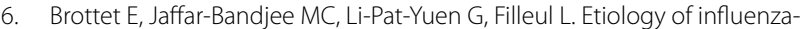
like illnesses from sentinel network practitioners in Reunion Island, 2011-2012. PLoS ONE. 2016:11(9):e0163377.

7. Foulongne V, Segondy M. Bocavirus humain (HBoV). In: Elsevier Masson 90-550022; 2008

8. Principi N, Piralla A, Zampiero A, Bianchini S, Umbrello G, Scala A, Bosis S, Fossali E, Baldanti F, Esposito S. Bocavirus infection in otherwise healthy children with respiratory disease. PLoS ONE. 2015;10(8):e0135640.

9. Kenmoe S, Tchendjou P, Vernet MA, Moyo-Tetang S, Mossus T, NjankouoRipa M, Kenne A, Penlap Beng V, Vabret A, Njouom R. Viral etiology of severe acute respiratory infections in hospitalized children in Cameroon, 2011-2013. Influenza Other Respir Viruses. 2016;10(5):386-93.

10. Lekana-Douki SE, Nkoghe D, Drosten C, Ngoungou EB, Drexler JF, Leroy EM. Viral etiology and seasonality of influenza-like illness in Gabon, March 2010 to June 2011. BMC Infect Dis. 2014;14:373.

11. Lekana-Douki SE, Kombila-Koumavor C, Nkoghe D, Drosten C, Drexler JF, Leroy EM. Molecular epidemiology of enteric viruses and genotyping of rotavirus A, adenovirus and astrovirus among children under 5 years old in Gabon. Int J Infect Dis. 2015;34:90-5.

12. Anisimova M, Gascuel O. Approximate likelihood-ratio test for branches: a fast, accurate, and powerful alternative. Syst Biol. 2006;55(4):539-52.

13. Dereeper A, Guignon V, Blanc G, Audic S, Buffet S, Chevenet F, Dufayard JF, Guindon S, Lefort V, Lescot M, et al. Phylogeny.fr: robust phylogenetic analysis for the non-specialist. Nucleic Acids Res. 2008;36(suppl_2):W465-9.

14. Guindon S, Dufayard JF, Lefort V, Anisimova M, Hordijk W, Gascuel O. New algorithms and methods to estimate maximum-likelihood phylogenies: assessing the performance of PhyML 3.0. Syst Biol. 2010;59(3):307-21.

15. Peltola V, Soderlund-Venermo $M$, Jartti T. Human bocavirus infections. Pediatr Infect Dis J. 2013;32(2):178-9.

16. Zhao B, Yu X, Wang C, Teng Z, Shen J, Gao Y, Zhu Z, Wang J, Yuan Z, Wu F, et al. High human bocavirus viral load is associated with disease severity in children under 5 years of age. PLoS ONE. 2013;8(4):e62318.

17. Misigo D, Mwaengo D, Mburu D. Molecular detection and phylogenetic analysis of Kenyan human bocavirus isolates. J Infect Dev Ctries. 2014:8(2):221-7

18. Tabasi M, Mokhtari-Azad T, Eshraghian MR, Shadab A, Shatizadeh S, Shafiei-Jandaghi NZ, Yavarian J. Human bocavirus infections among children less than 2 years old in Iran during fall and winter 2012-2013. Iran J Microbiol. 2016;8(1):80-4.

19. Khor CS, Sam IC, Hooi PS, Quek KF, Chan YF. Epidemiology and seasonality of respiratory viral infections in hospitalized children in Kuala Lumpur, Malaysia: a retrospective study of 27 years. BMC Pediatr. 2012;12:32.

20. Kwofie TB, Anane YA, Nkrumah B, Annan A, Nguah SB, Owusu M. Respiratory viruses in children hospitalized for acute lower respiratory tract infection in Ghana. Virol J. 2012;9:78.

21. Peltola V, Jartti T, Putto-Laurila A, Mertsola J, Vainionpaa R, Waris M, Hyypia T, Ruuskanen O. Rhinovirus infections in children: a retrospective and prospective hospital-based study. J Med Virol. 2009;81(10):1831-8.

22. Patel MM, Widdowson MA, Glass RI, Akazawa K, Vinje J, Parashar UD. Systematic literature review of role of noroviruses in sporadic gastroenteritis. Emerg Infect Dis. 2008;14(8):1224-31.

23. Tate JE, Burton AH, Boschi-Pinto C, Parashar UD, World Health Organization-Coordinated Global Rotavirus Surveillance N. Global, Regional, and National Estimates of Rotavirus Mortality in Children < 5 Years of Age, 2000-2013. Clin Infect Dis. 2016:62(Suppl 2):96-105.

24. Endo R, Ishiguro N, Kikuta H, Teramoto S, Shirkoohi R, Ma X, Ebihara T, Ishiko $H$, Ariga T. Seroepidemiology of human bocavirus in Hokkaido prefecture, Japan. J Clin Microbiol. 2007;45(10):3218-23.

25. Taylor S, Lopez P, Weckx L, Borja-Tabora C, Ulloa-Gutierrez R, LazcanoPonce E, Kerdpanich A, Angel Rodriguez Weber M, de Los Mascarenas, Santos A, Tinoco JC, et al. Respiratory viruses and influenza-like illness: epidemiology and outcomes in children aged 6 months to 10 years in a multi-country population sample. J Infect. 2016;74:29-41.

26. Niang MN, Diop OM, Sarr FD, Goudiaby D, Malou-Sompy H, Ndiaye K, Vabret A, Baril L. Viral etiology of respiratory infections in children under 5 years old living in tropical rural areas of Senegal: the EVIRA project. Med Virol. 2010;82(5):866-72.

27. Razanajatovo NH, Richard V, Hoffmann J, Reynes JM, Razafitrimo GM, Randremanana RV, Heraud JM. Viral etiology of influenza-like illnesses in Antananarivo, Madagascar, July 2008 to June 2009. PLoS ONE. 2011;6(3):e17579.

28. Schildgen O, Muller A, Allander T, Mackay IM, Volz S, Kupfer B, Simon A. Human bocavirus: passenger or pathogen in acute respiratory tract infections? Clin Microbiol Rev. 2008;21(2):291-304 (table of contents)

29. Guido M, Tumolo MR, Verri T, Romano A, Serio F, De Giorgi M, De Donno A, Bagordo F, Zizza A. Human bocavirus: current knowledge and future challenges. World J Gastroenterol. 2016;22(39):8684-97.

30. Proenca-Modena JL, Martinez M, Amarilla AA, Espinola EE, Galeano ME, Farina N, Russomando G, Aquino VH, Parra Gl, Arruda E. Viral load of human bocavirus-1 in stools from children with viral diarrhoea in Paraguay. Epidemiol Infect. 2013;141(12):2576-80.

31. Tymentsev A, Tikunov A, Zhirakovskaia E, Kurilschikov A, Babkin I, Klemesheva V, Netesov S, Tikunova N. Human bocavirus in hospitalized children with acute gastroenteritis in Russia from 2010 to 2012. Infect Genet Evol. 2016;37:143-9.

32. Wang $X$, Zhang $X$, Tian $H$, Ling $F$, Yu $M$, Sun $G$, Yang $S$, Shen $Q$, Wang $Y$, Shao $S$, et al. Complete genomes of three human bocavirus strains from children with gastroenteritis and respiratory tract illnesses in jiangsu, china. J Virol. 2012;86(24):13826-7.

33. Alam MM, Khurshid A, Shaukat S, Sharif S, Suleman RM, Angez M, Nisar N, Aamir UB, Naeem M, Zaidi SS. Human bocavirus in Pakistani children with gastroenteritis. J Med Virol. 2015;87(4):656-63.

34. Lee EJ, Kim HS, Kim HS, Kim JS, Song W, Kim M, Lee YK, Kang HJ. Human bocavirus in Korean children with gastroenteritis and respiratory tract infections. Biomed Res Int. 2016;2016:7507895.

35. Zhang DM, Ma MM, Wen WT, Zhu X, Xu L, He ZJ, He X, Wu JH, Hu YW, Zheng $Y$, et al. Clinical epidemiology and molecular profiling of human bocavirus in faecal samples from children with diarrhoea in Guangzhou, China. Epidemiol Infect. 2015;143(11):2315-29. 